Academic Platform Journal of Engineering and Science

\title{
Bulanık AHP ve Bulanık WASPAS Yaklaşımı ile Kaizen Öneri Sistemi Değerlendirme Modeli
}

\author{
*1 Merve Cengiz Toklu, ${ }^{2}$ İrem Bozkurt, ${ }^{3}$ Burcu Sekmen

\begin{abstract}
${ }^{1}$ Sakarya Üniversitesi, Endüstri Mühendisliği Bölümü, Turkey, mervetoklu@ sakarya.edu.tr,
${ }^{3}$ Sakarya Üniversitesi, Endüstri Mühendisliği Bölümü, Turkey, sekmenburcuu@ gmail.com,
\end{abstract} \\ ${ }^{2}$ Sakarya Üniversitesi, Endüstri Mühendisliği Bölümü, Turkey, irem.bozkurt@ ogr.sakarya.edu.tr, \\ Araştırma Makalesi \\ Geliş Tarihi: 18.06.2019 \\ Kabul Tarihi: 26.11.2019
}

$\ddot{O} z$

Sürekli iyileştirme, rekabet avantajını elinde tutmak isteyen işletmelerin benimsediği bir yaklaşımdır. İşletmelerin, mevcut durumu kabul etmeyerek kendilerini sürekli iyileştirme çabası içinde olmasının birçok nedeni bulunmaktadır. Bu nedenlerden bazıları ergonomik sebepler, iş sağlığı ve güvenliği zorunlulukları, maliyet azaltma hedefleri, kaliteli ürün elde etme ve rekabet avantajı sağlama amaçları olarak sayılabilir. İşletmelerdeki küçük fakat sürekli yapılan iyileştirmeler olarak ifade edilen Kaizen öneri sisteminin kalite, iş güvenliği, maliyetler ve verimlilik üzerinde olumlu etkileri uygulamada kanıtlanmış ve pek çok işletme tarafindan bu sistem benimsenmiştir. Kaizen yaklaşımı, her şeyin mükemmel olmadığı ve her zaman küçük iyileştirmelerin yapılabileceği üzerine geliştirilmiştir. Kaizen öneri sisteminde farklı bölümlerden ve/veya çalışanlardan aynı zaman diliminde pek çok iyileştirme önerisi gelebilmektedir. Bu durumda önerilerin önceliklendirilmesi ve öncelik sırasına göre uygulamaya geçilmesi gerekmektedir. Bu öncelikleri oluştururken birbirinden farklı pek çok kriter göz önünde bulundurulmalıdır. Bu çalışmada, Kaizen öneri sistemi kapsamında geliştirilen önerilerin değerlendirilmesi ve önceliklendirilmesi için bulanık mantık yaklaşımını içeren bir değerlendirme modeli önerilmiştir. Önerilen modelde, öncelikle değerlendirme kriterleri belirlenmiş olup bu kriterlerin önem dereceleri Bulanık AHP metodu ile hesaplanmıştır. Önerilerin değerlendirilmesi ve sıralanması ise Bulanık WASPAS metodu ile gerçekleştirilmiştir. Önerilen model bir otomotiv işletmesinde uygulanmıştır. Çalışmanın sonucunda, öncelik verilecek iyileştirme önerisi Tampon hazırlık sürecinde yaşanan verimsizliğin iyileştirilmesi olarak tespit edilmiştir.

Anahtar Kelimeler: Kalite, sürekli iyileştirme, Kaizen, AHP, WASPAS, bulanık mantık

\section{Kaizen Suggestion System Evaluation Model with Fuzzy AHP and Fuzzy WASPAS Approach}

\author{
*1 Merve Cengiz Toklu, ${ }^{2}$ İrem Bozkurt, ${ }^{3}$ Burcu Sekmen
}

\footnotetext{
${ }^{1}$ Sakarya University, Department of Industrial Engineering, Sakarya, Turkey, mervetoklu@ sakarya.edu.tr ${ }^{2}$ Sakarya University, Department of Industrial Engineering, Sakarya, Turkey, irem.bozkurt@ogr.sakarya.edu.tr

${ }^{3}$ Sakarya University, Department of Industrial Engineering, Sakarya, Turkey, sekmenburcuu@gmail.com
}

\begin{abstract}
Continuous improvement is an approach adopted by businesses that want to retain their competitive advantage. There are many reasons why businesses do not accept the current situation and constantly strive to improve themselves. Some of these reasons include ergonomic reasons, occupational health and safety obligations, cost reduction targets, quality products, and competitive advantage. The Kaizen suggestion system, which is referred to as small but continuous improvements in the companies, has proven positive effects on quality, safety, costs and productivity in practice and has been adopted by many companies. The Kaizen approach is based on the fact that not everything is perfect and that small improvements can always be made. In Kaizen suggestion system, many improvement suggestions can be received from different departments and / or employees in the same
\end{abstract}


time frame. In this case, the recommendations should be prioritized and implemented in order of priority. When setting these priorities, many different criteria should be considered. In this study, an evaluation model including fuzzy logic approach is proposed for the evaluation and prioritization of the proposals developed within the scope of Kaizen suggestion system. In the proposed model, firstly, evaluation criteria were determined and the importance of these criteria was calculated by Fuzzy AHP method. The evaluation and ranking of the suggestions were made by Fuzzy WASPAS method. The proposed model was applied in an automotive company. As a result of the study, the improvement proposal to be given priority was determined as improvement of the inefficiency during the buffer preparation process.

Keywords: Quality, continuous improvement, Kaizen, AHP, WASPAS, fuzzy logic

\section{GİRIS}

Kaizen maliyetleme sistemi, üretim maliyetlerini düşürmek için sürekli olarak uygulanan iyileştirme çalışmalarını içeren bir yaklaşımdır. Kaizen yaklaşımı, sadece imalat ya da hizmet sektöründeki iş süreçlerinde değil, yaşamın her alanında uygulanabilir bir felsefedir. Japoncada Kaizen "daha iyisi için değişmek", "gelişme” anlamına gelmektedir. $\mathrm{Bu}$ yaklaşımı ilk ortaya koyan kişi ise Masaaki IMAI'dir. Masaaki İmai tarafindan, Kaizen: Japonya'nın Rekabetteki Başarısının Anahtarı adı ile yayınlanan eser 1993 yılında Türkçe'ye çevrilmiştir. Kaizen maliyetleme sistemi; tam zamanında üretim, çalışma takımları, toplam verimli bakım, kaizen öneri sistemi ve poka yoke gibi teknikleri içermektedir. Kaizen önerileri ile kalitede artış, maliyetlerde azalma, iş kazalarında azalma, ergonomik problemlerde azalma ve teslim sürelerinde düşüş gibi pek çok fayda beklenmektedir. Ancak Kaizen önerileri geliştirirken önemsenmesi gereken en önemli noktalardan birisi de işletmenin mevcut kaynaklarının (iş gücü, makine, bütçe, fiziksel alan vb.) değerlendirilmesi ve yüksek maliyetler oluşturmadan değişikliklerin uygulanmasıdır. Kaizen çalışmalarının başarılı olabilmesi için operasyonel seviyeden stratejik seviyeye kadar yönetimin her kademesinde benimsenmesi ve desteklenmesi gerekmektedir. Kaizen çalışmaları işletmelerde bir kez uygulanan ya da sadece belirli dönemleri kapsayan bir kalite hareketi değildir. Kaizen yaklaşımının sürekliliğin sağlanması için çalışanların bu kapsamda eğitilmesi ve teşvik edilmesi gerekmektedir.

Kaizen öneri sistemini uygulayan şirketlerde kaizen izleme ve değerlendirme süreci mevcuttur. $\mathrm{Bu}$ süreçte çalışma grupları (kalite çemberleri) kaizen önerilerini sunarlar. Kısım, bölüm ve grup içerisindeki en iyi çalışmalar seçilir. Daha sonra finale kalan kaizen önerileri üst yönetim tarafından değerlendirilir ve en iyi öneri seçilir. Kısım, bölüm ve grupta en iyi çalışmalar seçilirken karar vericiler tarafindan kullanılan kisıtlı ve herhangi bir metodoloji içermeyen bir puanlandırma şablonu mevcuttur. Karar vericiler daha önceden belirlenen değerlendirme kriterleri kapsamında kaizenleri 1-5 arası puanlandırmaktadır.

Bu çalışmada, Kaizen öneri sistemi kapsamında sunulan Kaizen önerilerinin değerlendirilmesi ve önceliklendirilmesi için bulanık mantık yaklaşımını içeren bir model önerilmiştir. Önerilen modelde, değerlendirme kriterleri yeniden belirlenmiş olup bu kriterlerin önem dereceleri Bulanık AHP metodu ile hesaplanmıştır. Her bir değerlendirme kriteri ikili karşılaştırma matrisleri sayesinde birbiri ile mukayese edilebilmektedir. Daha sonraki aşamada ise kaizen önerilerinin sıralanması için Bulanık WASPAS metodundan faydalanılmıştır. Böylece değerlendirme sürecinin daha şeffaf ve sistematik bir yaklaşımla gerçekleştirilmesi hedeflenmiştir. Önerilen modelde kullanılan metotların bulanık mantık yaklaşımını içermesi sayesinde karar vericilerin dilsel ifadeleri sayısallaştırılabilmiştir. Önerilen model bir otomotiv işletmesinde uygulanmıştır.

Literatürde Kaizen maliyetleme sistemini içeren farklı çalışmalar mevcut olup, bu çalışmada önerilen benzer bir değerlendirme modeline rastlanılmamıştır. Brunet ve New [1] yaptıkları çalışmada öncelikle kaizen yaklaşımını ve metodolojisini açıklamıştır. Bununla birlikte, bir çelik firmasını otomotiv endüstrisindeki diğer firmalarla karşılaştıran bir çalışma gerçekleştirmişlerdir. Modarress, Ansari ve Lockwood [2] Boeing Ticari Uçak Şirket'nde uygulanan kaizen maliyetleme ile ilgili bir vaka analizi gerçekleştirmişlerdir. Altınbay [3], Kaizen maliyetleme sistemini bütünüyle ele alarak, tam zamanında üretim, çalışma takımları, toplam verimli bakım, öneri sistemi ve poka yoke olmak üzere 5 temel prensibinden bahsetmiştir. Bozdemir ve Orhan [4] Kaizen maliyetleme yönteminin Türkiye'de otomotiv sektöründe uygulanma düzeyini ölçmeyi amaçlamıştır. García, Rivera ve Iniesta [5] yaptıkları çalışmada kaizen için kritik başarı faktörlerini belirlemeyi amaçlamışlardır. Operatörlerin eğitimi, iletişim süreci, proje sonuçlarının belgelendirilmesi ve değerlendirilmesi, insan kaynakları entegrasyonu, yönetimin katılımı ve müşteri odaklılık başarı faktörlerinin en önemlileri olarak belirlenmiştir. Hacihasanoğlu [6] kaizen maliyetleme sistemini mobilya sektöründe uygulayarak üretim miktarında \%29 oranında bir iyileştirme sağlamıştır. Carnerud, Jaca ve Bäckström [7] 1980-2017 yılları arasında kaizen ve sürekli iyileştirme konularında yapılan çalışmaları ve bu iki konunun arasındaki ilişkiyi araştırmışlardır. Bellgran, Kurdve ve Hanna [8] yaptıkları çalışmada ilaç sektöründe yeşil kaizen yaklaşımını örneklendirmişlerdir.

Analitik Hiyerarşi Prosesi (AHP) yöntemi literatürde sıklıkla yer alan bir yöntem olup genellikle seçme, sıralama ve sınıflandırma amacıyla kullanılmaktadır. WASPAS yöntemi ise nispeten yeni geliştirilmiş bir çok kriterli karar verme yöntemi olmasına rağmen literatürde farklı problemlerin çözümünde kullanılmıştır. Staniunas vd. [9] sera gazı emisyonunu azaltmak için evlerin modernize edilmesinde COPRAS, WASPAS ve TOPSIS yöntemlerini birlikte 
kullanmışlardır. Madic vd. [10] parça işleme yönteminin seçiminde WASPAS yönteminden faydalanmıştır. Bagočiusa, Zavadskas ve Turskis [11] derin su limanı seçiminde Entropi ve WASPAS yöntemlerinin birlikte kullanmışlardır. Ghorabaee vd. [12] Aralık Tip-2 Bulanık WASPAS yöntemini yeşil tedarikçi seçimi probleminde kullanmıștır. Zavadskas, Kalibatas ve Kalibatiene [13] WASPAS yönteminden bina iç ortamında en uygun seçimi yapmak için faydalanmıştır. Aytaç Adalı ve Tuş Işıı [14] tedarikçi seçimi probleminin çözümünde SWARA ve WASPAS yöntemlerini birlikte kullanmıştır. Ghorabaee vd. [15] 3. parti lojistik sağlayıcısı seçiminde aralık Tip-2 bulanık WASPAS yöntemini kullanmışlardır. Çakır, Akel ve Doğaner [16] çalışmalarında SWARA ve WASPAS yöntemlerini birlikte kullanmış ve alışveriş sitelerini değerlendirmiştir. Bulanık AHP ve Bulanık WASPAS yöntemlerinin bir arada kullanan çalışmalar kısıtlı sayıda olup, 2015 yılında Turskis vd. [17] alışveriş merkezi için inşaat alanı seçiminde Bulanık AHP ve Bulanık WASPAS yöntemlerini kullanmışlardır.

Çalışmanın bundan sonraki kısmı genel olarak şu bölümlerden oluşmaktadır: Bölüm 2'de Bulanık AHP ve Bulanık WASPAS yöntemleri ele alınmıştır. Bölüm 3'te ise önerilen model anlatılmışıtır. Önerilen model bir otomotiv işletmesinde uygulanmış olup ilgili uygulama Bölüm 4'te verilmiştir. Sonuçlar Bölümü'nde uygulamanın sonuçları tartışılarak gelecek çalışmalardan bahsedilmiş̧ir.

\section{METODOLOJI}

\subsection{Bulanık AHP Yöntemi}

Analitik Hiyerarşi Prosesi metodu [18] alternatifleri ve/veya kriterleri seçmek, değerlendirmek ve önceliklendirmek için sıklıkla kullanılan bir çok kriterli karar verme yöntemidir. AHP yönteminde ağırlıklar (veya öncelikler) karar vericiler tarafindan yapılan ikili karşılaştırmaların sonuçlarından elde edilir. AHP yönteminde karar vericiler tarafindan ikili karşılaştırma matrisleri oluşturulurken dilsel ifadeler kullanılmasından dolayı Bulanı AHP yöntemi geliştirilmiştir. Literatürde, Bulanık AHP konusunda karar matrislerinin değerlendirilmesinde farklı yöntemler geliştirilmiş olup bu çalışmada, Chang [19] tarafindan 1996 yılında önerilen genişlemiş Bulanık AHP yöntemi kullanılmıştır. Chang'ın genişletilmiş Bulanık AHP yönteminin adımları aşağıda verilmiştir:

$X=\left\{x_{1}, x_{2}, \ldots, x_{n}\right\}$ nesneler kümesi, ve $G=\left\{g_{1}, g_{2}, \ldots, g_{m}\right\}$ amaç kümesi olsun. $M$ tane genişletilmiş analiz değeri elde edilmiş olup şu şekilde gösterilir:

$$
M_{g_{i}}^{1}, M_{g_{i}}^{2}, \ldots, M_{g_{i}}^{m}, \quad i=1,2, \ldots, n
$$

Burada tüm $M_{g_{i}}^{j}(j=1,2, \ldots, m)$ değerleri üçgensel bulanık sayılardır.

$$
S_{i}=\sum_{j}^{m} M_{g_{i}}^{j} \otimes\left[\sum_{i=1}^{n} \sum_{j=1}^{m} M_{g_{i}}^{j}\right]^{-1}
$$

$$
\begin{aligned}
& \sum_{j}^{m} M_{g_{i}}^{j}=\left(\sum_{j=1}^{m} l_{j}, \sum_{j=1}^{m} m_{j}, \sum_{j=1}^{m} u_{j}\right) \\
& \sum_{i=1}^{n} \sum_{j=1}^{m} M_{g_{i}}^{j}=\left(\sum_{i=1}^{n} l_{i}, \sum_{i=1}^{n} m_{i}, \sum_{i=1}^{n} u_{i}\right) \\
& {\left[\sum_{i=1}^{n} \sum_{j=1}^{m} M_{g_{i}}^{j}\right]^{-1}=\left(\frac{1}{\sum_{i=1}^{n} u_{i}}, \frac{1}{\sum_{i=1}^{n} m_{i}}, \frac{1}{\sum_{i=1}^{n} l_{i}}\right)}
\end{aligned}
$$

$M_{2}=\left(l_{2}, m_{2}, u_{2}\right)$ ve $M_{1}=\left(l_{1}, m_{1}, u_{1}\right)$ iki üçgensel bulanık sayı olmak üzere $M_{2}>M_{1}$ eşitliğinin olabilirlik derecesi aşağıda gösterilmiştir:

$$
\begin{gathered}
V\left(M_{2} \geq M_{1}\right)=\sup \left[\min \left(\mu_{M_{1}}(x), \mu_{M_{2}}(y)\right)\right] \\
V\left(M_{2} \geq M_{1}\right)=\operatorname{hgt}\left(M_{1} \cap M_{2}\right)=\mu_{M_{2}}(d) \\
=\left\{\begin{array}{cl}
1, & \text { if } m_{2} \geq m_{1}, \\
0, & \text { if } l_{1} \geq u_{2}, \\
\frac{l_{1}-u_{2}}{\left(m_{2}-u_{2}\right)-\left(m_{1}-l_{1}\right)}, & \text { otherwise, }
\end{array}\right.
\end{gathered}
$$

Buradaki d değeri $M_{1}$ ve $M_{2}$ üçgensel bulanık sayılarının kesişim noktasının ordinatıdır.

$M_{1}$ ve $M_{2}$ 'yi karşılaştrabilmek için hem $V\left(M_{1} \geq M_{2}\right)$ hem de $V\left(M_{2} \geq M_{1}\right)$ değerlerinin hesaplanması gerekmektedir. Konveks bir bulanık sayının $\mathrm{k}$ adet bulanık sayıdan, $\mathrm{M}_{\mathrm{i}}(\mathrm{i}=1$, $2, \ldots, k)$, daha büyük olma ihtimali şu şekilde tanımlanır:

$$
\begin{aligned}
& \begin{aligned}
V\left(M \geq M_{1}, M_{2}, \ldots, M_{k}\right) \\
\quad=V\left[\left(M \geq M_{1}\right) \text { and }(M\right. \\
\left.\left.\geq M_{2}\right) \text { and } \ldots \text { and }\left(M \geq M_{k}\right)\right]
\end{aligned} \\
& =\min V\left(M \geq M_{i}\right), \quad i=1,2, \ldots, k .
\end{aligned}
$$

O halde $S_{j}{ }^{\prime} l e r$ için şu varsayımlar yapılmıştır.

$$
k=1,2, \ldots, n ; k \neq i \text { için } d^{\prime}\left(A_{i}\right)=\min V\left(S_{i} \geq S_{k}\right)
$$

Daha sonra ağırlık vektörü $A_{i}(i=1,2, \ldots, n)$ 'nin n elemandan oluştuğu şu şekilde verilir:

$$
W^{\prime}=\left(d^{\prime}\left(A_{1}\right), d^{\prime}\left(A_{2}\right), \ldots, d^{\prime}\left(A_{n}\right)\right)^{T}
$$

Son olarak, normalizasyon işlemi ile normalize edilmiş vektör W'nin bulanık bir sayı olmadığı aşağıdaki denklem ile gösterilir.

$$
W=\left(d\left(A_{1}\right), d\left(A_{2}\right), \ldots, d\left(A_{n}\right)\right)^{T}
$$

\subsection{Bulanık WASPAS Yöntemi}

Ağırlıklandırılmış Bütünleşik Toplam Çarpım Değerlendirmesi (WASPAS), çok kriterli karar verme yöntemlerinden birisi olarak 2012 yılında Zavadskas vd. [20] tarafindan önerilmiştir. Daha sonra bu metot 2014 yilında Zavadskas vd. [21] tarafindan aralık değerli sezgisel bulanık sayılar kullanılarak geliştirilmiştir. 2015 yılında ise Bulanık WASPAS yönteminin adımları Turkis vd. [17] tarafindan aşağıdaki şekilde tanımlanmıştır. Keshavarz Ghorabaee vd. 
[12] ise 2016 yllında WASPAS metodunu Aralık Tip-2 bulanık sayıları kullanarak genişletmişlerdir. WASPAS "Ağırlıklı Toplam Modeli (Weighted Sum Model-WSM)" ve "Ağırlıklı Çarpım Modeli (Weighted Product ModelWPM)" olmak üzere iki farklı modelin sonuçlarını birleştiren çok kriterli karar verme yaklaşımıdır. Bulanık WASPAS adımları şu şekildedir:

Adım 1: Bulanık karar matrisinin oluşturulması: Karar matrisinin girdileri, i. alternatifin j. kritere göre bulanık performans değeri $\left(\tilde{x}_{i j}\right)$ ve ağırlığıdır $\left(\widetilde{w}_{j}\right)$. m adet alternatif ve $n$ adet kriter vardır.

$$
\tilde{X}=\left[\begin{array}{ccccc}
\tilde{x}_{11} & \cdots & \tilde{x}_{1 j} & \cdots & \tilde{x}_{1 n} \\
\vdots & \ddots & \vdots & \ddots & \vdots \\
\tilde{x}_{i 1} & \cdots & \tilde{x}_{i j} & \cdots & \tilde{x}_{i n} \\
\vdots & \ddots & \vdots & \ddots & \vdots \\
\tilde{x}_{m 1} & \cdots & \tilde{x}_{m j} & \cdots & \tilde{x}_{m n}
\end{array}\right] ; i=\overline{1, m}, j
$$

Adım 2: Normalize karar matrisinin oluşturulması: $\tilde{x}_{i j}$ başlangıç değerlerinin hepsi için normalizasyon işlemleri yapilir.

$$
\begin{aligned}
& \tilde{\bar{x}}_{i j}=\left\{\begin{array}{l}
\tilde{x}_{i j}=\frac{\tilde{x}_{i j}}{\max _{i} \tilde{x}_{i j}} \text { ĕger fayda kriteri ise } \\
\tilde{x}_{i j}=\frac{\min _{i} \tilde{x}_{i j}}{\tilde{x}_{i j}} \text { eğer maliyet kriteri ise }
\end{array}\right. \\
& i=\overline{1, m}, j=\overline{1, n}
\end{aligned}
$$

Adım 3: Ağırlıklı normalize edilmiş bulanık karar matrisinin $\left(\tilde{X}_{q}\right)$ Ağırlıklı Toplam Modeli (WSM) için hesaplanması:

$$
\tilde{\hat{X}}_{q}=\left[\begin{array}{ccccc}
\tilde{\hat{x}}_{11} & \cdots & \tilde{\hat{x}}_{1 j} & \cdots & \tilde{\hat{x}}_{1 n} \\
\vdots & \ddots & \vdots & \ddots & \vdots \\
\tilde{\hat{x}}_{i 1} & \cdots & \tilde{\hat{x}}_{i j} & \cdots & \tilde{\hat{x}}_{i n} \\
\vdots & \ddots & \vdots & \ddots & \vdots \\
\tilde{\hat{x}}_{m 1} & \cdots & \tilde{\hat{x}}_{m j} & \cdots & \tilde{\hat{x}}_{m n}
\end{array}\right]
$$

$$
\tilde{\hat{x}}_{i j}=\tilde{\bar{x}}_{i j} \widetilde{w}_{j} ; i=\overline{1, m}, j=\overline{1, n}
$$

Ağırlıklı normalize edilmiş bulanık karar matrisinin $\left(\widetilde{\hat{X}}_{p}\right)$ Ağırlıklı Çarpım Modeli (WPM) için hesaplanması:

$$
\begin{aligned}
& \widetilde{\tilde{X}}_{p}=\left[\begin{array}{ccccc}
\tilde{\overline{\bar{x}}}_{11} & \ldots & \tilde{\overline{\bar{x}}}_{1 j} & \ldots & \widetilde{\overline{\bar{x}}}_{1 n} \\
\vdots & \ddots & \vdots & \ddots & \vdots \\
\widetilde{\overline{\bar{x}}}_{i 1} & \ldots & \tilde{\overline{\bar{x}}}_{i j} & \ldots & \widetilde{\overline{\bar{x}}}_{i n} \\
\vdots & \ddots & \vdots & \ddots & \vdots \\
\widetilde{\overline{\bar{x}}}_{m 1} & \ldots & \widetilde{\overline{\bar{x}}}_{m j} & \ldots & \widetilde{\overline{\bar{x}}}_{m n}
\end{array}\right] \\
& \widetilde{\overline{\bar{x}}}_{i j}=\widetilde{\bar{x}}_{i j} \widetilde{w}_{j} ; i=\overline{1, m}, j=\overline{1, n}
\end{aligned}
$$

Turskis vd. [17] birden fazla karar vericiden ayrı ayrı elde edilen kriter ağırlıklarını bütünleştirmek için aşağıdaki yöntemi önermişleridir. $n$ kriter için bulanık grup ağırlıkları
$\widetilde{W}=\left[\widetilde{\widetilde{w}_{1}, \widetilde{w}_{n}}\right]=\left[\widetilde{w}_{j}\right]$ aşağıdaki gibi elde edilir $\left(\widetilde{w}_{j}\right.$ bulanık üçgensel sayıdır):

$$
\tilde{x}_{j}=\left(x_{j \alpha}, x_{j \beta}, x_{j \gamma}\right)
$$

j kriter ağırlığının mümkün olan minimum değeri:

$w_{j \alpha}=\min _{k} y_{j k}, \quad y_{j k} \mathrm{k}$ uzman tarafindan belirlenen $\mathrm{j}$ kriter ağırlığgidır, $j=\overline{1, n}, k=\overline{1, p}$,

j kriter ağırlığının en olası değeri:

$w_{j \beta}=\left(\prod_{k=1}^{p} y_{j k}\right)^{1 / p}, j=\overline{1, n}$,

j kriter ağırlığının mümkün olan maksimum değeri: $w_{j \gamma}=$ $\max _{k} y_{j k}, j=\overline{1, n}, k=\overline{1, p}$

Adım 4: Optimallik fonksiyon değerlerinin hesaplanması:

a) Her bir alternatif için Ağırlıklı Toplam Modeline göre aşağıdaki gibi hesaplanır.

$$
\tilde{Q}_{i}=\sum_{j=1}^{n} \widetilde{\hat{x}}_{i j} ; i=\overline{1, m}
$$

b) Her bir alternatif için Ağırlıklı Çarpım Modeline göre aşağıdaki gibi hesaplanır.

$$
\tilde{P}_{i}=\prod_{j=1}^{n} \tilde{\overline{\bar{x}}}_{i j} ; i=\overline{1, m}
$$

Her bir alternatif için bulanık performans ölçümünün sonucu olan $\tilde{Q}_{i}$ ve $\tilde{P}_{i}$ değerleri bulanık sayılardır. Bulanık sayıları durulaştırma işlemi aşağıdaki eşitliklerle yapılır.

$$
\begin{aligned}
Q_{i} & =\frac{1}{3}\left(Q_{i \alpha}+Q_{i \beta}+Q_{i \gamma}\right) \\
P_{i} & =\frac{1}{3}\left(P_{i \alpha}+P_{i \beta}+P_{i \gamma}\right)
\end{aligned}
$$

Adım 5: Bulanık WASPAS yönteminin her bir alternatif için bütünleşik fayda fonksiyon değeri aşağıdaki gibi belirlenebilir.

$$
K_{i}=\lambda \sum_{j=1}^{m} Q_{i}+(1-\lambda) \sum_{j=1}^{m} P_{i}
$$

$$
\lambda=0, \ldots, 1,0 \leq K_{i} \leq 1
$$

$\lambda$ değeri belirlenirken, tüm alternatifler için Ağırlıklı Toplam Modelinin, Ağırlıklı Çarpım Modeli puanlarına eşit olması gerektiği varsayılmaktadır.

$$
\lambda=\frac{\sum_{i=1}^{m} P_{i}}{\sum_{i=1}^{m} Q_{i}+\sum_{i=1}^{m} P_{i}}
$$

Adım 6: Son olarak, alternatifler $K_{i}$ değerlerine göre sıralanır. En büyük $K_{i}$ değerine sahip olan alternatif en uygun alternatiftir. Alternatifler için $K_{i}$ değerlerine bakılarak uygunluk sırası oluşturulabilir. 


\section{3. ÖNERILLEN MODEL}

İşletmeler gelişen teknolojiye uyum sağlamak ve aynı zamanda rekabet avantajı sağlamak için sürekli iyileştirme felsefesini benimsemektedirler. Kaizen öneri sistemi de sürekli iyileştirme felsefesi kapsamında işletmeler tarafından tercih edilen bir yöntemdir. Kaizenler işletme içerisinde küçük iyileştirmeler olarak görülse de uzun vadede etkisi oldukça yüksek olabilmektedir. Kaizen öneri sisteminin çalışanlar tarafından benimsenmesi amacıyla genellikle teşvik amaçlı ödül sistemi de uygulanmaktadır. Çalışanlar tarafindan geliştirilen önerilerin bir metot ile değerlendirilmesi ve önceliklendirilmesi hem Kaizen öneri sisteminin verimliliğini arttıracak hem de ödül sisteminin adil olarak uygulanmasına destek olacaktır. Bu çalışmada Kaizen öneri sistemi kapsamında yapılan önerilerin sistematik olarak değerlendirilmesini sağlayan bir model önerilmiştir. Kaizen önerileri değerlendirilirken göz önünde bulundurulması gereken birçok kriter vardır. Şekil 1'de görüldüğü gibi Kaizen önerilerinin değerlendirilmesi için Kaizen Türü, Çalışan Türü, Risk, Kalite Maliyeti ve Tasarruf olmak üzere 5 ana kriter ve her bir ana kritere ait alt kriterler belirlenmiştir. $\mathrm{Bu}$ kriterler önerilen modelin uygulandığ işletmedeki uzmanların görüşü alınarak belirlenmiştir.

Kaizen Türü: çalışanlar tarafından pek çok farklı konuda iyileştirme önerileri gelebilmektedir. Bazı iyileştirmeler tamamen maliyet odaklı iken bazıları İş Sağlığı ve Güvenliği (İSG) açısından riskleri ortadan kaldırmaya yönelik önerilerdir. Dolayısıyla öncelikle önerilerin hangi amaca yönelik olduğunu belirlemek gerekmektedir. Bu kapsamda öneriler maliyet, bireysel gelişim, kalite, çevre ve ISG olmak üzere 5 ana başlık altında değerlendirilmektedir.

Çalışan Türü: Önerilerin gerçekleştirilmesi durumunda iyileştirmenin odağında olacak grubu ifade eder. $\mathrm{Bu}$ kapsamda ofis çalışanı, üretim çalışanı ve yardımcı tesisler çalışanı olmak üzere 3 ana grup mevcuttur.

Risk: Önerilen her bir kaizen olası bir riski önlemeyi de amaçlar. $\mathrm{Bu}$ risk bazen hatalı parçanın son kullanıcıya (müşteriye) ulaşması iken bazen yeniden işleme maliyeti bazen de iş kazası olarak ortaya çıkabilir. Önerilen kaizenler risk kriteri kapsamında, belirlenen riskin şiddeti, kazenin riski yok etme etkisi, problemin müşteriye kaçış riski ve riskin ortaya çıkış sıklığı olmak üzere 4 ana başlıkta incelenmektedir.

Kalite Maliyeti: Kaizen öneri sistemindeki felsefe küçük adımlarla fakat sürekli olarak iyileştirme yapılmasını içerir. Önerilen kaizenlerin gerçekleştirme maliyetlerinin kazanımları karşısında çok daha düşük olması hedeflenir. Bununla birlikte önerilen kaizenlerin gerçekleştirilmemesi durumunda ortaya çıacak maliyetlerin de belirlenmesi önem arz eder. İlgili kaizen gerçekleştirilmeyecekse bundan dolayı oluşacak maliyetlere katlanılacaktır.

Tasarruf: Tam olarak önerinin işletmeye ne kazandıracağ ile ilgili bir kriterdir. İş gücü tasarrufu, stok miktarında tasarruf, süreçlerde gerçekleşecek bir tasarruf ve fabrika alanından tasarruf olmak üzere 4 başlıkta değerlendirme yapilacaktır.

Kriterlerin ağırlıkları Bulanık AHP metodu ile hesaplanmaktadır. Çalışanlar tarafından önerilen Kaizenlerin her biri birer alternatif gibi değerlendirilerek Bulanık WAPSAS metodu ile sıralanmaktadır. Önerilen model sonucunda ortaya çıkan sıra kaizen önerilerini gerçekleştirme sırası olarak değerlendirilmektedir.

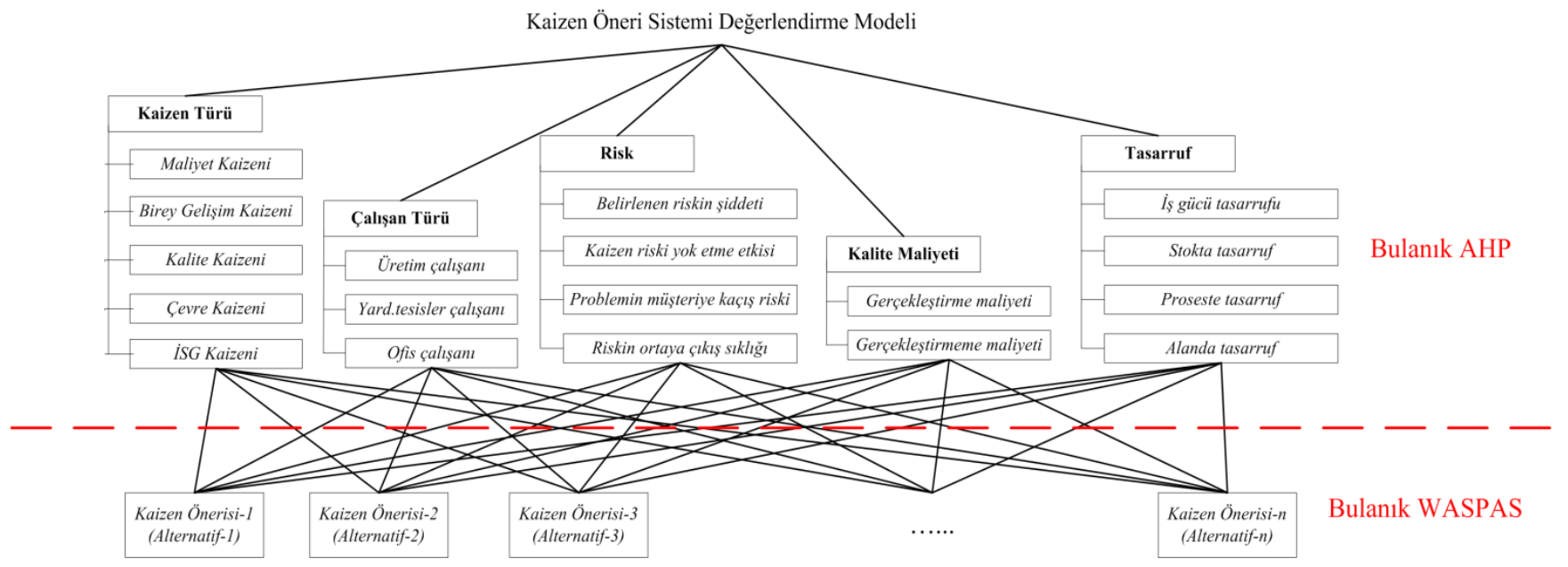

Şekil 1. Kaizen öneri sistemi değerlendirme modeli

\section{UYGULAMA}

$\mathrm{Bu}$ çalışma kapsamında geliştirilen model bir otomotiv firmasında uygulanmıştır. Geliştirilen modelde Kaizen önerilerinin değerlendirilmesi için ilk adım olan kriter ağırlıklarının belirlenmesi Bulanık AHP yöntemi ile gerçekleştirilirken alternatiflerin yani kaizen önerilerinin sırası ise Bulanık WASPAS yöntemi ile hesaplanmıştır. 
Geliştirilen modelin uygulandığ1 işletmede toplam 11 adet kaizen önerilmiş olup bu öneriler Tablo 1'de verilmiştir.

Tablo 1. Çalışanlar tarafindan sunulan Kaizen önerileri

\begin{tabular}{ll}
\hline $\begin{array}{l}\text { Kaizen } \\
\text { Num. }\end{array}$ & Kaizen Açıklaması \\
\hline $\mathrm{A}_{1}$ & $\begin{array}{l}\text { Boyalı parçaların taşınmasında yaşanan } \\
\text { problemlerin iyileştirilmesi }\end{array}$ \\
\hline $\mathrm{A}_{2}$ & $\begin{array}{l}\text { Tampon hazırlık prosesinde yaşanan } \\
\text { verimsizliğin iyileştirilmesi }\end{array}$ \\
\hline $\mathrm{A}_{3}$ & $\begin{array}{l}\text { Test esnasında oluşan yüksek sesin } \\
\text { iyileştirilmesi }\end{array}$ \\
\hline $\mathrm{A}_{4}$ & İzolasyon sac kırılmalarının iyileştirilmesi \\
\hline $\mathrm{A}_{5}$ & Mekanik ayak montaj zorluğunun iyileştirilmesi \\
\hline $\mathrm{A}_{6}$ & $\begin{array}{l}\text { Alt boşaltım prosesinde oluşan ergonomik } \\
\text { zorlukların iyileştirilmesi }\end{array}$ \\
\hline $\mathrm{A}_{7}$ & $\begin{array}{l}\text { Çamurluk prosesinde yaşanan zaman } \\
\text { kayıplarının iyileştirilmesi }\end{array}$ \\
\hline $\mathrm{A}_{8}$ & $\begin{array}{l}\text { Model üretim planına göre senaryo } \\
\text { hazırlanması }\end{array}$ \\
\hline $\mathrm{A}_{9}$ & Yapılan işlerde detay eksikliğinin iyileştirilmesi \\
\hline $\mathrm{A}_{10}$ & $\begin{array}{l}\text { Montaj hattı girişinde boya rötuş işleminin } \\
\text { yapılması }\end{array}$ \\
\hline $\mathrm{A}_{11}$ & Müşteri şikâyet modelinin iyileştirilmesi \\
\hline
\end{tabular}

Öncelikle işletme bünyesindeki bulunan yalın ofiste çalışan 3 adet üst düzey yetkili çalışan, karar verici (KV) olarak belirlenmiştir. Karar vericiler tarafindan ilk olarak kriterler değerlendirilmiştir. Bulanık AHP yöntemi ile ana kriterlerin ve alt kriterlerin ağırlıkları belirlendikten sonra alt kriterlere ait global ağırlıklar belirlenmiştir. Karar vericiler, kriterleri karşılaştırırken önemli, daha önemli gibi dilsel ifadeler kullanmışlardır. Bu ifadeler Tablo 2 kullanılarak bulanık üçgensel sayılara dönüştürülmüştür. Kriterlerin ağırlıkları Eşitlik (1)-(10) kullanılarak hesaplanmıştır.

Bulanık WASPAS yönteminin ilk adımı olarak, karar vericiler başlangıç bulanık karar verme matrisini belirlemişlerdir. $\mathrm{Bu}$ matris belirlenirken kullanılan dilsel ifadeler Tablo 6 kullanılarak sayısallaştırılmıştır. Başlangıç bulanık karar verme matrisi Tablo 7'de verilmiştir. Bir sonraki adımda ise Eşitlik (12) kullanılarak başlangıç bulanık karar verme matrisi normalize edilmiştir (Tablo 8). Burada K11 ve K41 alt kriterleri maliyet kriteri olarak ele alınmış olup hesaplamalar bu durum dikkate alınarak gerçekleştirilmiştir. Örneğin K11 kriteri için öncelikle Tablo 7'den alınan değerlerin en küçüğü belirlenir. Burada dikkat edilmesi gereken nokta K11 kriteri bir maliyet kriteridir bu nedenle en küçüğü belirlenmiştir.

$\operatorname{Min}(7,9,10,3,5,7,7,9,10,5,7,9,5,7,9,7,9,10,7,9,10,3,5,7,5,7,9$ $, 5,7,9,9,10,10)=3$

Daha sonra Tablo 7'de yer alan ve K11 kriteri için belirlenen her bir , $\beta$ ve $\gamma$ değeri için aşağıdaki işlem yapılır.

$3 / 7=0.429 ; 3 / 9=0.333 ; 3 / 10=0.3$

K12 kriteri ise pozitif bir kriter olduğu için Tablo 7'den alınan değerlerin en büyüğü belirlenir.
Tablo 2. Kriterlere ait dilsel ifadeler ve bulanık üçgensel sayılar

\begin{tabular}{lll}
\hline Dilsel ifadeler & $\begin{array}{l}\text { Bulanık } \\
\text { üçgensel } \\
\text { sayılar }\end{array}$ & $\begin{array}{l}\text { Bulanık } \\
\text { üçgensel } \\
\text { sayıların tersi }\end{array}$ \\
\hline Eşit önemli & $(1,1,1)$ & $(1,1,1)$ \\
\hline Az önemli & $(1,3,5)$ & $(1 / 5,1 / 3,1)$ \\
\hline Önemli & $(3,5,7)$ & $(1 / 7,1 / 5,1 / 3)$ \\
\hline Daha önemli & $(5,7,9)$ & $(1 / 9,1 / 7,1 / 5)$ \\
\hline Kesinlikle daha önemli & $(7,9,9)$ & $(1 / 9,1 / 9,1 / 7)$ \\
\hline
\end{tabular}

Tablo 3'te karar verici 1'e ait ana kriterlerin ikili karşılaştırma matrisi örnek olarak verilmiștir. Her bir karar verici önce ana kriterleri daha sonra alt kriterleri karşılaştırarak değerlendirmiştir. Tablo 4'te ise tüm karar vericilere ait alt kriterlerin global ağırlıkları listelenmiştir. Bulanık AHP ile belirlenen ve Tablo 4'te verilen her bir karar vericinin ayr ayrı belirlediği ağırlıklar daha sonra WASPAS yönteminde kullanılmak üzere bütünleştirilmiştir (Tablo 5). Tablo 5'te yer alan $\alpha, \beta$ ve $\gamma$ değerleri Eşitlik (15) kullanılarak hesaplanmıştır. Örneğin K11 kriteri için karar vericilerin görüşleri Bulanık AHP yöntemiyle değerlendirildikten sonra sırasıyla $0.0677,0.0605$ ve 0.0599 olarak belirlenmiştir.

K11 kriter ağırlığının mümkün olan minimum değeri: $\min (0.0677,0.0605,0.0599)=0.0599$

K11 kriter ağırlığının en olası değeri: $(0.0677 \times 0.0605 \times 0.0599)^{1 / 3}=0.0626$

K11 kriter ağırlığının mümkün olan maksimum değeri: $\operatorname{maks}(0.0677, \quad 0.0605, \quad 0.0599)=0.0677 \quad$ olarak hesaplanmıştır.

Kriter ağırlıkları Bulanık AHP yöntemi ile belirlendikten sonra Kaizen önerileri Bulanık WASPAS yöntemi ile sıralanmıştır.

$\operatorname{Maks}(9,10,10,9,10,10,5,7,9,9,10,10,5,7,9,7,9,10,3,5,7,5,7,9$, $7,9,10,9,10,10,3,5,7)=10$

Daha sonra Tablo 7'de yer alan ve K12 kriteri için belirlenen her bir $\alpha, \beta$ ve $\gamma$ değeri için işlemler yapılır. 9/10=0.9 ; $10 / 10=1 ; 10 / 10=1$

Eşitlik (13) ve Eşitlik (14) kullanılarak Ağırlıklı Toplam Modeli ve Ağırlıklı Çarpım Modeli için ağırlıklı normalize edilmiş bulanık karar matrisi hesaplanmıștır. Daha sonra Eşitlik (16)- Eşitlik (19) kullanılarak Optimallik fonksiyon değerleri hesaplanmıştır. Tablo 9'da sadece alternatif 1'e ait Ağırlıklı Toplam Modeli ve Ağırlıklı Çarpım Modeli için ağırlıklı normalize edilmiş bulanık karar matrisi örnek olarak gösterilmiştir. Son olarak, Eşitlik (20) ve Eşitlik (21) kullanılarak Bulanık WASPAS yönteminin her bir alternatif için bütünleşik fayda fonksiyon değeri hesaplanmıştır. Kaizen önerileri (alternatifler) belirlenen $K_{i}$ değerlerine göre büyükten küçüğe sıralanmış olup, bu değerler Tablo 10'da verilmiştir.

Örneğin Alternatif 1 için;

$\sum \mathrm{p}_{\mathrm{i}}=0.695+0.798+0.664+0.676+0.735+0.728+0.674+0.77$ $0+0.768+0.740+0.724=7.972$ 
$\sum \mathrm{Q}_{\mathrm{i}}=0.740+0.829+0.714+0.727+0.765+0.768+0.717+0.79$

$2+0.807+0.772+0.768=8.401$

$\lambda=7.972 /(7.972+8.401)=0.487$
Alternatif 1 için bütünleşik fayda fonksiyon değeri $\mathrm{K}_{1}$ aşağıdaki şekilde hesaplanmıştır.

$(0.487 \times 0.740)+(1-0.487) \times 0.695=0.717$

Tablo 3. Karar Verici 1'e ait ana kriterlerin ikili karşılaştırma matrisi

\begin{tabular}{llllll}
\hline & Kaizen türü & Çalışan türü & Risk & Kalite maliyetleri & Tasarruf \\
\hline Kaizen türü & $(1 ; 1 ; 1)$ & $(5 ; 7 ; 9)$ & $(1 ; 3 ; 5)$ & $(3 ; 5 ; 7)$ & $(1 ; 3 ; 5)$ \\
\hline Çalışan türü & $(0.11 ; 0.14 ; 0.2)$ & $(1 ; 1 ; 1)$ & $(0.14 ; 0.2 ; 0.33)$ & $(1 ; 3 ; 5)$ & $(0.2 ; 0.33 ; 1)$ \\
\hline Risk & $(0.2 ; 0.33 ; 1)$ & $(3 ; 5 ; 7)$ & $(1 ; 1 ; 1)$ & $(3 ; 5 ; 7)$ & $(1 ; 3 ; 5)$ \\
\hline Kalite maliyetleri & $(0.14 ; 0.2 ; 0.33)$ & $(0.2 ; 0.33 ; 1)$ & $(0.14 ; 0.2 ; 0.33)$ & $(1 ; 1 ; 1)$ & $(1 ; 3 ; 5)$ \\
\hline Tasarruf & $(0.2 ; 0.33 ; 1)$ & $(1 ; 3 ; 5)$ & $(0.2 ; 0.33 ; 1)$ & $(0.2 ; 0.33 ; 1)$ & $(1 ; 1 ; 1)$ \\
\hline
\end{tabular}

Tablo 4. Tüm karar vericilere ait alt kriterlerin global ağırlıkları

\begin{tabular}{|c|c|c|c|c|}
\hline \multirow{2}{*}{ Ana Kriter } & \multirow{2}{*}{ Alt kriterler } & \multicolumn{3}{|c|}{ Karar Vericiler } \\
\hline & & $\mathrm{KV}_{1}$ & $\mathrm{KV}_{2}$ & $\mathrm{KV}_{3}$ \\
\hline \multirow{5}{*}{ Kaizen türü } & K11 Maliyet & 0.0677 & 0.0605 & 0.0599 \\
\hline & K12 Birey Gelişimi & 0.0186 & 0.0166 & 0.0164 \\
\hline & K13 Kalite & 0.1059 & 0.0945 & 0.0937 \\
\hline & K14 Çevre & 0.0554 & 0.0495 & 0.0490 \\
\hline & K15 İş Güvenliği & 0.1017 & 0.0908 & 0.0900 \\
\hline \multirow{3}{*}{ Çalışan türü } & K21 Üretim Çalışanı & 0.0603 & 0.0722 & 0.0780 \\
\hline & K22 Yardımcı Tesisler & 0.0054 & 0.0065 & 0.0070 \\
\hline & K23 Ofis Çalışanı & 0.0395 & 0.0473 & 0.0511 \\
\hline \multirow{4}{*}{ Risk } & K31 Belirlenen Riskin Şiddeti & 0.0496 & 0.0473 & 0.0465 \\
\hline & K32 Kaizenin Riski Yok Etme Etkisi & 0.0840 & 0.0801 & 0.0788 \\
\hline & K33 Problemin Müşteriye Kaçış Riski & 0.1182 & 0.1127 & 0.1109 \\
\hline & K34 Riskin Ortaya Çıkış Sıklığı & 0.0508 & 0.0484 & 0.0477 \\
\hline \multirow{2}{*}{ Kalite maliyetleri } & K41 Gerçekleştirme Maliyeti & 0.0542 & 0.0630 & 0.0624 \\
\hline & K42 Gerçekleştirmeme Maliyeti & 0.0542 & 0.0630 & 0.0624 \\
\hline \multirow{4}{*}{ Tasarruf } & K51 İş Gücü Tasarrufu & 0.0507 & 0.0556 & 0.0550 \\
\hline & K52 Stokta Tasarruf & 0.0447 & 0.0489 & 0.0485 \\
\hline & K53 Proseste Tasarruf & 0.0302 & 0.0331 & 0.0328 \\
\hline & K54 Alanda Tasarruf & 0.0091 & 0.0100 & 0.0099 \\
\hline
\end{tabular}

Tablo 5. Bütünleştirilmiş kriter ağırlıkları

\begin{tabular}{|c|c|c|c|c|c|c|c|c|c|c|c|c|c|}
\hline \multirow[b]{2}{*}{ Kriterler } & \multicolumn{3}{|c|}{ Karar Vericiler } & \multicolumn{3}{|c|}{$\mathrm{W}$} & \multicolumn{4}{|c|}{ Karar Vericiler } & \multicolumn{3}{|c|}{$\mathrm{W}$} \\
\hline & $\mathrm{KV}_{1}$ & $\mathrm{KV}_{2}$ & $\mathrm{KV}_{3}$ & $\alpha$ & $\beta$ & $\gamma$ & Kriterler & $\mathrm{KV}_{1}$ & $\mathrm{KV}_{2}$ & $\mathrm{KV}_{3}$ & $\alpha$ & $\beta$ & $\gamma$ \\
\hline K11 & 0.0677 & 0.0605 & 0.0599 & 0.0599 & 0.0626 & 0.0677 & K32 & 0.084 & 0.0801 & 0.0788 & 0.0788 & 0.081 & 0.084 \\
\hline K12 & 0.0186 & 0.0166 & 0.0164 & 0.0164 & 0.0172 & 0.0186 & K33 & 0.1182 & 0.1127 & 0.1109 & 0.1109 & 0.1139 & 0.1182 \\
\hline K13 & 0.1059 & 0.0945 & 0.0937 & 0.0937 & 0.0979 & 0.1059 & K34 & 0.0508 & 0.0484 & 0.0477 & 0.0477 & 0.0489 & 0.0508 \\
\hline K14 & 0.0554 & 0.0495 & 0.049 & 0.049 & 0.0512 & 0.0554 & K41 & 0.0542 & 0.063 & 0.0624 & 0.0542 & 0.0597 & 0.063 \\
\hline K15 & 0.1017 & 0.0908 & 0.09 & 0.09 & 0.094 & 0.1017 & K42 & 0.0542 & 0.063 & 0.0624 & 0.0542 & 0.0597 & 0.063 \\
\hline $\mathrm{K} 21$ & 0.0603 & 0.0722 & 0.078 & 0.0603 & 0.0698 & 0.078 & K51 & 0.0507 & 0.0556 & 0.055 & 0.0507 & 0.0537 & 0.0556 \\
\hline $\mathrm{K} 22$ & 0.0054 & 0.0065 & 0.007 & 0.0054 & 0.0062 & 0.007 & K52 & 0.0447 & 0.0489 & 0.0485 & 0.0447 & 0.0473 & 0.0489 \\
\hline $\mathrm{K} 23$ & 0.0395 & 0.0473 & 0.0511 & 0.0395 & 0.0457 & 0.0511 & K53 & 0.0302 & 0.0331 & 0.0328 & 0.0302 & 0.032 & 0.0331 \\
\hline K31 & 0.0496 & 0.0473 & 0.0465 & 0.0465 & 0.0478 & 0.0496 & K54 & 0.0091 & 0.01 & 0.0099 & 0.0091 & 0.0097 & 0.01 \\
\hline
\end{tabular}

Tablo 6. Alternatiflere ait dilsel ifadeler ve bulanık üçgensel sayılar [22]

\begin{tabular}{llll}
\hline Dilsel İfadeler & $\alpha$ & $\beta$ & $\gamma$ \\
\hline Önemsiz & 0 & 1 & 1 \\
\hline Az Önemli & 1 & 3 & 5 \\
\hline Orta Önemli & 3 & 5 & 7 \\
\hline Önemli & 5 & 7 & 9 \\
\hline Çok Önemli & 7 & 9 & 10 \\
\hline Kesinlikle Çok Önemli & 9 & 10 & 10 \\
\hline
\end{tabular}


Tablo 7. Başlangıç bulanık karar verme matrisi

Çalışanlar tarafindan yapılan Kaizen Önerileri (Alternatifler)

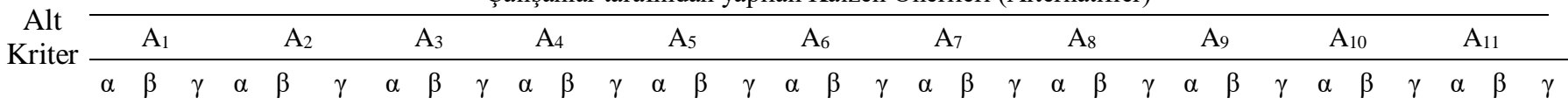
\begin{tabular}{lllllllllllllllllllllllllllllllllllllllll}
$\mathrm{K} 11$ & 7 & 9 & 10 & 3 & 5 & 7 & 7 & 9 & 10 & 5 & 7 & 9 & 5 & 7 & 9 & 7 & 9 & 10 & 7 & 9 & 10 & 3 & 5 & 7 & 5 & 7 & 9 & 5 & 7 & 9 & 9 & 10 & 10 \\
\hline
\end{tabular} \begin{tabular}{lllllllllllllllllllllllllllllllllll}
$\mathrm{K} 12$ & 9 & 10 & 10 & 9 & 10 & 10 & 5 & 7 & 9 & 9 & 10 & 10 & 5 & 7 & 9 & 7 & 9 & 10 & 3 & 5 & 7 & 5 & 7 & 9 & 7 & 9 & 10 & 9 & 10 & 10 & 3 & 5 & 7 \\
\hline
\end{tabular} $\begin{array}{lllllllllllllllllllllllllllllllllllllllllllll}\mathrm{K} 13 & 9 & 10 & 10 & 9 & 10 & 10 & 5 & 7 & 9 & 3 & 5 & 7 & 7 & 9 & 10 & 7 & 9 & 10 & 3 & 5 & 7 & 5 & 7 & 9 & 9 & 10 & 10 & 7 & 9 & 10 & 9 & 10 & 10\end{array}$ \begin{tabular}{lllllllllllllllllllllllllllllllllll}
$\mathrm{K} 14$ & 3 & 5 & 7 & 3 & 5 & 7 & 9 & 10 & 10 & 3 & 5 & 7 & 5 & 7 & 9 & 7 & 9 & 10 & 5 & 7 & 9 & 5 & 7 & 9 & 5 & 7 & 9 & 5 & 7 & 9 & 5 & 7 & 9 \\
\hline
\end{tabular} $\begin{array}{llllllllllllllllllllllllllllllllllllllll}\mathrm{K} 15 & 5 & 7 & 9 & 5 & 7 & 9 & 9 & 10 & 10 & 7 & 9 & 10 & 7 & 9 & 10 & 9 & 10 & 10 & 5 & 7 & 9 & 5 & 7 & 9 & 9 & 10 & 10 & 7 & 9 & 10 & 7 & 9 & 10\end{array}$ \begin{tabular}{llllllllllllllllllllllllllllllllllll}
$\mathrm{K} 21$ & 9 & 10 & 10 & 9 & 10 & 10 & 9 & 10 & 10 & 9 & 10 & 10 & 9 & 10 & 10 & 9 & 10 & 10 & 9 & 10 & 10 & 7 & 9 & 10 & 9 & 10 & 10 & 7 & 9 & 10 & 7 & 9 & 10 \\
\hline
\end{tabular} \begin{tabular}{lllllllllllllllllllllllllllllllllllllll}
$\mathrm{K} 22$ & 3 & 5 & 7 & 3 & 5 & 7 & 9 & 10 & 10 & 3 & 5 & 7 & 3 & 5 & 7 & 3 & 5 & 7 & 3 & 5 & 7 & 3 & 5 & 7 & 3 & 5 & 7 & 3 & 5 & 7 & 7 & 9 & 10 \\
\hline
\end{tabular} \begin{tabular}{lllllllllllllllllllllllllllllllllll}
$\mathrm{K} 23$ & 7 & 9 & 10 & 5 & 7 & 9 & 7 & 9 & 10 & 5 & 7 & 9 & 5 & 7 & 9 & 7 & 9 & 10 & 5 & 7 & 9 & 9 & 10 & 10 & 7 & 9 & 10 & 9 & 10 & 10 & 9 & 10 & 10 \\
\hline
\end{tabular} \begin{tabular}{llllllllllllllllllllllllllllllllllll}
$\mathrm{K} 31$ & 9 & 10 & 10 & 7 & 9 & 10 & 7 & 9 & 10 & 9 & 10 & 10 & 7 & 9 & 10 & 7 & 9 & 10 & 7 & 9 & 10 & 5 & 7 & 9 & 9 & 10 & 10 & 7 & 9 & 10 & 9 & 10 & 10 \\
\hline
\end{tabular} \begin{tabular}{llllllllllllllllllllllllllllllllllll}
$\mathrm{K} 32$ & 7 & 9 & 10 & 9 & 10 & 10 & 9 & 10 & 10 & 9 & 10 & 10 & 7 & 9 & 10 & 7 & 9 & 10 & 9 & 10 & 10 & 9 & 10 & 10 & 7 & 9 & 10 & 9 & 10 & 10 & 7 & 9 & 10 \\
\hline
\end{tabular} \begin{tabular}{lllllllllllllllllllllllllllllllllll}
$\mathrm{K} 33$ & 3 & 5 & 7 & 7 & 9 & 10 & 3 & 5 & 7 & 9 & 10 & 10 & 5 & 7 & 9 & 5 & 7 & 9 & 7 & 9 & 10 & 7 & 9 & 10 & 7 & 9 & 10 & 5 & 7 & 9 & 9 & 10 & 10 \\
\hline
\end{tabular} $\begin{array}{llllllllllllllllllllllllllllllllllllllllll}\mathrm{K} 34 & 9 & 10 & 10 & 9 & 10 & 10 & 9 & 10 & 10 & 7 & 9 & 10 & 9 & 10 & 10 & 9 & 10 & 10 & 9 & 10 & 10 & 7 & 9 & 10 & 9 & 10 & 10 & 9 & 10 & 10 & 5 & 7 & 9\end{array}$ \begin{tabular}{lllllllllllllllllllllllllllllllllllll}
$\mathrm{K} 41$ & 3 & 5 & 7 & 5 & 7 & 9 & 5 & 7 & 9 & 7 & 9 & 10 & 5 & 7 & 9 & 5 & 7 & 9 & 5 & 7 & 9 & 3 & 5 & 7 & 7 & 9 & 10 & 5 & 7 & 9 & 5 & 7 & 9 \\
\hline
\end{tabular} \begin{tabular}{llllllllllllllllllllllllllllllllllll}
$\mathrm{K} 42$ & 5 & 7 & 9 & 7 & 9 & 10 & 3 & 5 & 7 & 3 & 5 & 7 & 5 & 7 & 9 & 3 & 5 & 7 & 3 & 5 & 7 & 7 & 9 & 10 & 5 & 7 & 9 & 5 & 7 & 9 & 5 & 7 & 9 \\
\hline
\end{tabular}

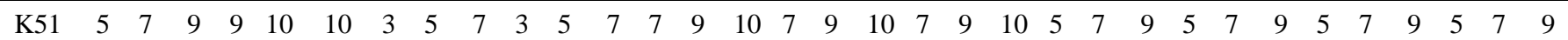

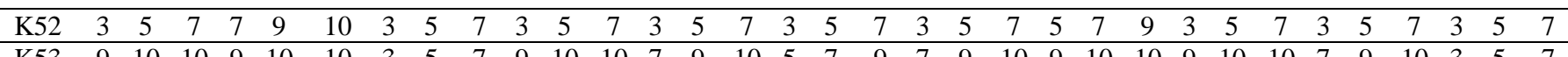

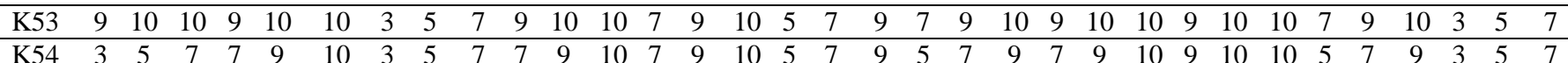

Tablo 8. Normalize edilmiş bulanık karar verme matrisi

\begin{tabular}{|c|c|c|c|c|c|c|c|c|c|c|c|c|}
\hline \multirow{2}{*}{$\begin{array}{l}\text { Alt } \\
\text { Kriter }\end{array}$} & \multicolumn{3}{|c|}{$\mathrm{A}_{1}$} & \multicolumn{3}{|c|}{$\mathrm{A}_{2}$} & \multicolumn{3}{|c|}{$\mathrm{A}_{3}$} & \multicolumn{3}{|c|}{$\mathrm{A}_{4}$} \\
\hline & $\alpha$ & $\beta$ & $\gamma$ & $\alpha$ & $\beta$ & $\gamma$ & $\alpha$ & $\beta$ & $\gamma$ & $\alpha$ & $\beta$ & $\gamma$ \\
\hline K11 & 0.429 & 0.333 & 0.300 & 1.000 & 0.600 & 0.429 & 0.429 & 0.333 & 0.300 & 0.600 & 0.429 & 0.333 \\
\hline K12 & 0.900 & 1.000 & 1.000 & 0.900 & 1.000 & 1.000 & 0.500 & 0.700 & 0.900 & 0.900 & 1.000 & 1.000 \\
\hline K13 & 0.900 & 1.000 & 1.000 & 0.900 & 1.000 & 1.000 & 0.500 & 0.700 & 0.900 & 0.300 & 0.500 & 0.700 \\
\hline K14 & 0.300 & 0.500 & 0.700 & 0.300 & 0.500 & 0.700 & 0.900 & 1.000 & 1.000 & 0.300 & 0.500 & 0.700 \\
\hline K15 & 0.500 & 0.700 & 0.900 & 0.500 & 0.700 & 0.900 & 0.900 & 1.000 & 1.000 & 0.700 & 0.900 & 1.000 \\
\hline K21 & 0.900 & 1.000 & 1.000 & 0.900 & 1.000 & 1.000 & 0.900 & 1.000 & 1.000 & 0.900 & 1.000 & 1.000 \\
\hline K22 & 0.300 & 0.500 & 0.700 & 0.300 & 0.500 & 0.700 & 0.900 & 1.000 & 1.000 & 0.300 & 0.500 & 0.700 \\
\hline K23 & 0.700 & 0.900 & 1.000 & 0.500 & 0.700 & 0.900 & 0.700 & 0.900 & 1.000 & 0.500 & 0.700 & 0.900 \\
\hline K31 & 0.900 & 1.000 & 1.000 & 0.700 & 0.900 & 1.000 & 0.700 & 0.900 & 1.000 & 0.900 & 1.000 & 1.000 \\
\hline K32 & 0.700 & 0.900 & 1.000 & 0.900 & 1.000 & 1.000 & 0.900 & 1.000 & 1.000 & 0.900 & 1.000 & 1.000 \\
\hline K33 & 0.300 & 0.500 & 0.700 & 0.700 & 0.900 & 1.000 & 0.300 & 0.500 & 0.700 & 0.900 & 1.000 & 1.000 \\
\hline K34 & 0.900 & 1.000 & 1.000 & 0.900 & 1.000 & 1.000 & 0.900 & 1.000 & 1.000 & 0.700 & 0.900 & 1.000 \\
\hline K41 & 1.000 & 0.600 & 0.429 & 0.600 & 0.429 & 0.333 & 0.600 & 0.429 & 0.333 & 0.429 & 0.333 & 0.300 \\
\hline K42 & 0.500 & 0.700 & 0.900 & 0.700 & 0.900 & 1.000 & 0.300 & 0.500 & 0.700 & 0.300 & 0.500 & 0.700 \\
\hline K51 & 0.500 & 0.700 & 0.900 & 0.900 & 1.000 & 1.000 & 0.300 & 0.500 & 0.700 & 0.300 & 0.500 & 0.700 \\
\hline K52 & 0.300 & 0.500 & 0.700 & 0.700 & 0.900 & 1.000 & 0.300 & 0.500 & 0.700 & 0.300 & 0.500 & 0.700 \\
\hline K53 & 0.900 & 1.000 & 1.000 & 0.900 & 1.000 & 1.000 & 0.300 & 0.500 & 0.700 & 0.900 & 1.000 & 1.000 \\
\hline K54 & 0.300 & 0.500 & 0.700 & 0.700 & 0.900 & 1.000 & 0.300 & 0.500 & 0.700 & 0.700 & 0.900 & 1.000 \\
\hline
\end{tabular}

Tablo 8 (devam). Normalize edilmiş bulanık karar verme matrisi

\begin{tabular}{|c|c|c|c|c|c|c|c|c|c|c|c|c|}
\hline \multirow{2}{*}{$\begin{array}{c}\text { Alt } \\
\text { Kriter }\end{array}$} & \multicolumn{3}{|c|}{$\mathrm{A}_{5}$} & \multicolumn{3}{|c|}{$\mathrm{A}_{6}$} & \multicolumn{3}{|c|}{$\mathrm{A}_{7}$} & \multicolumn{3}{|c|}{$\mathrm{A}_{8}$} \\
\hline & $\alpha$ & $\beta$ & $\gamma$ & $\alpha$ & $\beta$ & $\gamma$ & $\alpha$ & $\beta$ & $\gamma$ & $\alpha$ & $\beta$ & $\gamma$ \\
\hline K11 & 0.600 & 0.429 & 0.333 & 0.429 & 0.333 & 0.300 & 0.429 & 0.333 & 0.300 & 1.000 & 0.600 & 0.429 \\
\hline K12 & 0.500 & 0.700 & 0.900 & 0.700 & 0.900 & 1.000 & 0.300 & 0.500 & 0.700 & 0.500 & 0.700 & 0.900 \\
\hline K13 & 0.700 & 0.900 & 1.000 & 0.700 & 0.900 & 1.000 & 0.300 & 0.500 & 0.700 & 0.500 & 0.700 & 0.900 \\
\hline K14 & 0.500 & 0.700 & 0.900 & 0.700 & 0.900 & 1.000 & 0.500 & 0.700 & 0.900 & 0.500 & 0.700 & 0.900 \\
\hline K15 & 0.700 & 0.900 & 1.000 & 0.900 & 1.000 & 1.000 & 0.500 & 0.700 & 0.900 & 0.500 & 0.700 & 0.900 \\
\hline K21 & 0.900 & 1.000 & 1.000 & 0.900 & 1.000 & 1.000 & 0.900 & 1.000 & 1.000 & 0.700 & 0.900 & 1.000 \\
\hline K22 & 0.300 & 0.500 & 0.700 & 0.300 & 0.500 & 0.700 & 0.300 & 0.500 & 0.700 & 0.300 & 0.500 & 0.700 \\
\hline K23 & 0.500 & 0.700 & 0.900 & 0.700 & 0.900 & 1.000 & 0.500 & 0.700 & 0.900 & 0.900 & 1.000 & 1.000 \\
\hline K31 & 0.700 & 0.900 & 1.000 & 0.700 & 0.900 & 1.000 & 0.700 & 0.900 & 1.000 & 0.500 & 0.700 & 0.900 \\
\hline
\end{tabular}




\begin{tabular}{ccccccccccccc}
\hline K32 & 0.700 & 0.900 & 1.000 & 0.700 & 0.900 & 1.000 & 0.900 & 1.000 & 1.000 & 0.900 & 1.000 & 1.000 \\
\hline K33 & 0.500 & 0.700 & 0.900 & 0.500 & 0.700 & 0.900 & 0.700 & 0.900 & 1.000 & 0.700 & 0.900 & 1.000 \\
\hline K34 & 0.900 & 1.000 & 1.000 & 0.900 & 1.000 & 1.000 & 0.900 & 1.000 & 1.000 & 0.700 & 0.900 & 1.000 \\
\hline K41 & 0.600 & 0.429 & 0.333 & 0.600 & 0.429 & 0.333 & 0.600 & 0.429 & 0.333 & 1.000 & 0.600 & 0.429 \\
\hline K42 & 0.500 & 0.700 & 0.900 & 0.300 & 0.500 & 0.700 & 0.300 & 0.500 & 0.700 & 0.700 & 0.900 & 1.000 \\
\hline K51 & 0.700 & 0.900 & 1.000 & 0.700 & 0.900 & 1.000 & 0.700 & 0.900 & 1.000 & 0.500 & 0.700 & 0.900 \\
\hline K52 & 0.300 & 0.500 & 0.700 & 0.300 & 0.500 & 0.700 & 0.300 & 0.500 & 0.700 & 0.500 & 0.700 & 0.900 \\
\hline K53 & 0.700 & 0.900 & 1.000 & 0.500 & 0.700 & 0.900 & 0.700 & 0.900 & 1.000 & 0.900 & 1.000 & 1.000 \\
\hline K54 & 0.700 & 0.900 & 1.000 & 0.500 & 0.700 & 0.900 & 0.500 & 0.700 & 0.900 & 0.700 & 0.900 & 1.000 \\
\hline
\end{tabular}

Tablo 8 (devam). Normalize edilmiş bulanık karar verme matrisi

\begin{tabular}{cccccccccc}
\hline Alt & \multicolumn{3}{c}{$\mathrm{A}_{9}$} & \multicolumn{9}{c}{$\mathrm{A}_{10}$} & \multicolumn{3}{c}{$\mathrm{A}_{11}$} \\
$\mathrm{nyyyyyyyyy}$ Kriter & $\alpha$ & $\beta$ & $\gamma$ & $\alpha$ & $\beta$ & $\gamma$ & $\alpha$ & $\beta$ & $\gamma$ \\
\hline $\mathrm{K} 11$ & 0.600 & 0.429 & 0.333 & 0.600 & 0.429 & 0.333 & 0.333 & 0.300 & 0.300 \\
\hline $\mathrm{K} 12$ & 0.700 & 0.900 & 1.000 & 0.900 & 1.000 & 1.000 & 0.300 & 0.500 & 0.700 \\
\hline $\mathrm{K} 13$ & 0.900 & 1.000 & 1.000 & 0.700 & 0.900 & 1.000 & 0.900 & 1.000 & 1.000 \\
\hline $\mathrm{K} 14$ & 0.500 & 0.700 & 0.900 & 0.500 & 0.700 & 0.900 & 0.500 & 0.700 & 0.900 \\
\hline $\mathrm{K} 15$ & 0.900 & 1.000 & 1.000 & 0.700 & 0.900 & 1.000 & 0.700 & 0.900 & 1.000 \\
\hline $\mathrm{K} 21$ & 0.900 & 1.000 & 1.000 & 0.700 & 0.900 & 1.000 & 0.700 & 0.900 & 1.000 \\
\hline $\mathrm{K} 22$ & 0.300 & 0.500 & 0.700 & 0.300 & 0.500 & 0.700 & 0.700 & 0.900 & 1.000 \\
\hline $\mathrm{K} 23$ & 0.700 & 0.900 & 1.000 & 0.900 & 1.000 & 1.000 & 0.900 & 1.000 & 1.000 \\
\hline $\mathrm{K} 31$ & 0.900 & 1.000 & 1.000 & 0.700 & 0.900 & 1.000 & 0.900 & 1.000 & 1.000 \\
\hline $\mathrm{K} 32$ & 0.700 & 0.900 & 1.000 & 0.900 & 1.000 & 1.000 & 0.700 & 0.900 & 1.000 \\
\hline $\mathrm{K} 33$ & 0.700 & 0.900 & 1.000 & 0.500 & 0.700 & 0.900 & 0.900 & 1.000 & 1.000 \\
\hline $\mathrm{K} 34$ & 0.900 & 1.000 & 1.000 & 0.900 & 1.000 & 1.000 & 0.500 & 0.700 & 0.900 \\
\hline $\mathrm{K} 41$ & 0.429 & 0.333 & 0.300 & 0.600 & 0.429 & 0.333 & 0.600 & 0.429 & 0.333 \\
\hline $\mathrm{K} 42$ & 0.500 & 0.700 & 0.900 & 0.500 & 0.700 & 0.900 & 0.500 & 0.700 & 0.900 \\
\hline $\mathrm{K} 51$ & 0.500 & 0.700 & 0.900 & 0.500 & 0.700 & 0.900 & 0.500 & 0.700 & 0.900 \\
\hline $\mathrm{K} 52$ & 0.300 & 0.500 & 0.700 & 0.300 & 0.500 & 0.700 & 0.300 & 0.500 & 0.700 \\
\hline $\mathrm{K} 53$ & 0.900 & 1.000 & 1.000 & 0.700 & 0.900 & 1.000 & 0.300 & 0.500 & 0.700 \\
\hline $\mathrm{K} 54$ & 0.900 & 1.000 & 1.000 & 0.500 & 0.700 & 0.900 & 0.300 & 0.500 & 0.700 \\
\hline
\end{tabular}

Tablo 9. Alternatif 1 için Ağırlıklı Toplam Modeli ve Ağırlıklı Çarpım Modeli için ağırlıklı normalize edilmiş bulanık karar matrisi

\begin{tabular}{cccccccc}
\hline & \multicolumn{3}{c}{ A ğırlıklı Toplam Modeli } & \multicolumn{3}{c}{ Ăğılıklı Çarpım Modeli } \\
\hline Kriter & $\alpha$ & $\beta$ & $\gamma$ & Kriter & $\alpha$ & $\beta$ & $\gamma$ \\
\hline K11 & 0.026 & 0.021 & 0.020 & K11 & 0.950 & 0.934 & 0.922 \\
K12 & 0.015 & 0.017 & 0.019 & K12 & 0.998 & 1.000 & 1.000 \\
K13 & 0.084 & 0.098 & 0.106 & K13 & 0.990 & 1.000 & 1.000 \\
K14 & 0.015 & 0.026 & 0.039 & K14 & 0.943 & 0.965 & 0.980 \\
K15 & 0.045 & 0.066 & 0.092 & K15 & 0.940 & 0.967 & 0.989 \\
K21 & 0.054 & 0.070 & 0.078 & K21 & 0.994 & 1.000 & 1.000 \\
K22 & 0.002 & 0.003 & 0.005 & K22 & 0.994 & 0.996 & 0.998 \\
K23 & 0.028 & 0.041 & 0.051 & K23 & 0.986 & 0.995 & 1.000 \\
K31 & 0.042 & 0.048 & 0.050 & K31 & 0.995 & 1.000 & 1.000 \\
K32 & 0.055 & 0.073 & 0.084 & K32 & 0.972 & 0.992 & 1.000 \\
K33 & 0.033 & 0.057 & 0.083 & K33 & 0.875 & 0.924 & 0.959 \\
K34 & 0.043 & 0.049 & 0.051 & K34 & 0.995 & 1.000 & 1.000 \\
K41 & 0.054 & 0.036 & 0.027 & K41 & 1.000 & 0.970 & 0.948 \\
K42 & 0.027 & 0.042 & 0.057 & K42 & 0.963 & 0.979 & 0.993 \\
K51 & 0.025 & 0.038 & 0.050 & K51 & 0.965 & 0.981 & 0.994 \\
K52 & 0.013 & 0.024 & 0.034 & K52 & 0.948 & 0.968 & 0.983 \\
K53 & 0.027 & 0.032 & 0.033 & K53 & 0.997 & 1.000 & 1.000 \\
K54 & 0.003 & 0.005 & 0.007 & K54 & 0.989 & 0.993 & 0.996 \\
\hline Qi & 0.591 & 0.744 & 0.884 & Pi & 0.593 & 0.708 & 0.784 \\
\hline QiduRU & 0.740 & & \multicolumn{7}{c}{ PiduRU } & 0.695 & &
\end{tabular}


Tablo 10. Her bir Kaizen önerisine ait bütünleşik fayda fonksiyon değerleri

\begin{tabular}{cccccccccccc}
\hline & $\mathrm{A}_{1}$ & $\mathrm{~A}_{2}$ & $\mathrm{~A}_{3}$ & $\mathrm{~A}_{4}$ & $\mathrm{~A}_{5}$ & $\mathrm{~A}_{6}$ & $\mathrm{~A}_{7}$ & $\mathrm{~A}_{8}$ & $\mathrm{~A}_{9}$ & $\mathrm{~A}_{10}$ & $\mathrm{~A}_{11}$ \\
\hline $\mathrm{Q}$ & 0.740 & 0.829 & 0.714 & 0.727 & 0.765 & 0.768 & 0.717 & 0.792 & 0.807 & 0.772 & 0.768 \\
\hline $\mathrm{P}$ & 0.695 & 0.798 & 0.664 & 0.676 & 0.735 & 0.728 & 0.674 & 0.770 & 0.768 & 0.740 & 0.724 \\
\hline$\lambda$ & & & & & & 0.487 & & & & & \\
\hline $\mathrm{K}_{\mathrm{i}}$ & 0.717 & 0.813 & 0.688 & 0.701 & 0.750 & 0.748 & 0.695 & 0.781 & 0.787 & 0.756 & 0.745 \\
\hline Sira & 8 & 1 & 11 & 9 & 5 & 6 & 10 & 3 & 2 & 4 & 7 \\
\hline
\end{tabular}

\section{SONUÇ}

İşletmeler gerek çekirdek süreçlerinde gerekse yardımcı süreçlerinde sürekli iyileştirmeler sayesinde sistemlerinin güncelliğini koruyabilmektedir. Söz konusu iyileştirmelerin büyük maliyetler ile sonuçlanan ve kazanımı çok kısa dönemde hızla gözlemlenebilen faaliyetler olabileceği gibi, çok daha düşük maliyet ile daha dar kapsamlı fakat sürekli yapılan iyileştirme faaliyetler de olabilmektedir. $\mathrm{Bu}$ çalışmada düşük maliyetli, küçük adımlı fakat sürekli olarak gerçekleştirilen iyileştirme felsefesini içeren kaizen öneri sistemi ele alınarak, bu sistem kapsamında işletme çalışanları tarafindan sunulan kaizen önerilerini değerlendirmek üzere bir model geliştirilmiştir. Modelin amacı önerilen iyileştirmelerin belirli kriterlere göre sıralanması ve bu sıra dikkate alınarak uygulanmasıdır. Önerilen modelde, kaizen önerilerinin önceliklendirilmesinde Bulanık AHP ve Bulanık WASPAS yöntemleri birlikte kullanılmıştır. Çalışmada, ana kriter ve ilgili alt kriterlerin ağırlıklandırılmasında Bulanık AHP yöntemi kullanılırken, kaizen önerilerinin sıralamasında Bulanık WASPAS yöntemi kullanılmıştır. Kaizen önerilerinin önceliklendirilesi sayesinde modeli uygulayan işletme tarafindan kaizen önerilerinin uygulama süreci planlanarak kı1 kaynaklar etkin bir şekilde ihtiyaçlara yönelik dağıtılabilmektedir. Modelde, önerilen kaizenler; kaizen türü, çalışan türü, risk, kalite maliyetleri ve tasarruf olmak üzere 5 ana kriter 1şı ğında değerlendirilmiştir. Her bir ana kriterin kendi içinde alt kriterleri de mevcuttur. Toplamda 18 alt kriter belirlenmiştir.

Önerilen model bir otomotiv işletmesinde uygulanmıştır. $\mathrm{Bu}$ işletmede çalışanlar tarafindan önerilen 11 kaizen değerlendirilmiş ve önceliklendirilmiştir. Uygulama sonucunda elde edilen siralama incelendiğinde, öncelikle 2 numaralı kaizen önerisinin (tampon hazırlık prosesinde yaşanan verimsizliğin iyileştirilmesi) uygulamaya alınması sonucuna varılmıştır. $\mathrm{Bu}$ durum 2 numaralı kaizenin diğer kaizenlere göre öncelikli olduğu anlamına gelmektedir. Bir sonraki iyileştirme ise 9 numaralı kaizen (yapılan işlerde detay eksikliğinin iyileştirilmesi) olarak tespit edilmiştir. İşletmede yeterli kaynak mevcut ise önceliklendirilen kaizenler mümkün olduğunca paralel olarak uygulamaya alınabilir. En son siralarda yer alan kaizen önerileri ise daha sonra yapılmak üzere planlama listesine alınır.

Gelecek çalışmalarda farklı değerlendirme kriterleri eklenerek model genişletilebilir. Bununla birlikte mevcut değerlendirme yöntemi olan Bulanık WASPAS yerine Aralık Tip-2 Bulanık WASPAS yöntemi kullanılarak sonuçlar karşılaştırılabilir.

\section{KAYNAKÇA}

[1] A. P. Brunet and S. New, "Kaizen in Japan: An empirical study," Int. J. Oper. Prod. Manag., vol. 23, no. 12, pp. 1426-1446, 2003.

[2] B. Modarress, A. Ansari, and D. L. Lockwood, "Kaizen costing for lean manufacturing: A case study," Int. J. Prod. Res., vol. 43, no. 9, pp. 1751-1760, 2005.

[3] A. Altinbay, "Kaizen Maliyetleme Sistemi: Dinamik Bir Maliyet Yöntemi Sistemi," Afyon Kocatepe Üniversitesi İ.̇̇.B.F. Derg., vol. 8, no. 1, pp. 103-121, 2006. [4] E. Bozdemir and M. S. Orhan, "Üretim Maliyetlerinin Düşürülmesinde Kaizen Maliyetleme Yönteminin Rolü ve Uygulanabilirliğine Yönelik Bir Araştırma," Atatürk Üniversitesi Sos. Bilim. Enstitüsü Derg., vol. 15, no. 2, pp. 463-480, 2011.

[5] J. L. García, D. G. Rivera, and A. A. Iniesta, "Critical success factors for Kaizen implementation in manufacturing industries in Mexico," Int. J. Adv. Manuf. Technol., vol. 68, no. 1-4, pp. 537-545, 2013.

[6] T. Hacihasanoğlu, "Üretim maliyetlerinin düşürülmesinde kaizen malşyetkeme yöntemi ve mobilya sektöründe bir uygulama," Ekon. ve Sos. Araştırmalar Derg., vol. 10, no. 2, pp. 47-64, 2014.

[7] D. Carnerud, C. Jaca, and I. Bäckström, "Kaizen and continuous improvement - trends and patterns over 30 years," TQM J., vol. 30, no. 4, pp. 371-390, 2018.

[8] M. Bellgran, M. Kurdve, and R. Hanna, "Cost driven green kaizen in pharmaceutical production - Creating positive engagement for environmental improvements," Procedia CIRP, vol. 81, pp. 1219-1224, 2019.

[9] M. Staniūnas, M. Medineckienè, E. K. Zavadskas, and D. Kalibatas, "To modernize or not: Ecologicaleconomical assessment of multi-dwelling houses modernization," Arch. Civ. Mech. Eng., vol. 13, no. 1, pp. 88-98, 2013.

[10] M. Madić, V. Gecevska, M. Radovanović, and D. Petković, "Multi-criteria economic analysis of machining processes using the WASPAS method," J. Prod. Eng., vol. 17, no. 2, pp. 79-82, 2014.

[11] V. Bagočius, K. E. Zavadskas, and Z. Turskis, "Multi-criteria selection of a deep-water port in Klaipeda," Procedia Eng., vol. 57, pp. 144-148, 2013.

[12] M. K. Ghorabaee, E. K. Zavadskas, M. Amiri, and A. Esmaeili, "Multi-criteria evaluation of green suppliers 
using an extended WASPAS method with interval type-2 fuzzy sets," J. Clean. Prod., vol. 137, pp. 213-229, 2016.

[13] E. K. Zavadskas, D. Kalibatas, and D. Kalibatiene, "A multi-attribute assessment using WASPAS for choosing an optimal indoor environment," Arch. Civ. Mech. Eng., vol. 16, no. 1, pp. 76-85, 2016.

[14] E. Aytaç Adalı and A. Tuş Işsı, "Bir Tedarikçi Seçim Problemi İçin SWARA ve WASPAS Yöntemlerine Dayanan Karar Verme Yaklaşımı," Int. Rev. Econ. Manag., vol. 5, no. 4, pp. 56-77, 2017.

[15] M. K. Ghorabaee, M. Amiri, E. K. Zavadskas, and J. Antuchevičienè, "Assessment of third-party logistics providers using a CRITIC-WASPAS approach with interval type-2 fuzzy sets," Transport, vol. 32, no. 1, pp. 66-78, 2017. [16] E. Çakır, G. Akel, and M. Doğaner, "Türkiye'de faaliyet gösteren özel alışveriş sitelerinin bütünleşik SWARA-WASPAS yöntemi ile değerlendirilmesi," Uluslararası İktisadi ve İdari İncelemeler Derg., no. 18. EYİ Özel Sayıs1, pp. 599-616, 2018.

[17] Z. Turskis, E. K. Zavadskas, J. Antucheviciene, and N. Kosareva, "A hybrid model based on fuzzy AHP and fuzzy WASPAS for construction site selection," Int. J.
Comput. Commun. Control, vol. 10, no. 6, pp. 873-888, 2015.

[18] T. L. Saaty, The analytic hierarchy process. New York, USA: McGraw-Hill, 1980.

[19] D.-Y. Chang, "Applications of the extent analysis method on fuzzy AHP," Eur. J. Oper. Res., vol. 95, no. 3, pp. 649-655, 1996.

[20] E. K. Zavadskas, Z. Turskis, J. Antucheviciene, and A. Zakarevicius, "Optimization of weighted aggregated sum product assessment," Elektron. ir Elektrotechnika, vol. 122, no. 6, pp. 3-6, 2012.

[21] E. K. Zavadskas, J. Antucheviciene, S. H. Razavi Hajiagha, and S. S. Hashemi, "Extension of weighted aggregated sum product assessment with interval-valued intuitionistic fuzzy numbers (WASPAS-IVIF)," Appl. Soft Comput., vol. 24, pp. 1013-1021, 2014.

[22] Z. Turskis, N. Goranin, A. Nurusheva, and S. Boranbayev, "A fuzzy WASPAS-based approach to determine critical information infrastructures of EU sustainable development," Sustain., vol. 11, no. 2, p. 424, 2019. 